\title{
Optimization Embedded in Simulation on Models Type System Dynamics - Some Case Study
}

\author{
Elżbieta Kasperska and Damian Słota \\ Institute of Mathematics, Silesian University of Technology, Kaszubska 23, \\ 44-100 Gliwice, Poland \\ $\{$ e.kasperska, d.slota\}@polsl.pl
}

\begin{abstract}
The problem of optimization embedded in simulation on models type System Dynamics is rather new for field modelers. In model DYNBALANCE(2-2-c) authors link the algorithm of solving the pseudosolution of overdetermined system of equations to classical structure of type System Dynamics - to minimize the specific Euclidean norm which measures some aspect of the dynamical behaviour of system.
\end{abstract}

\section{Introduction}

The classical concept of system Dynamics [1,2,3,4,10,11, assumes, that, during the time horizon of the simulation, the structure (given a-priori) will remain constant. Last couple of years, some ideas of structural evolution has occurred in System Dynamics modelling. First prof. Coyle [1 took the problem of, so called "simulation during optimization". The question was: how to "optimize" the structure in order to achieve the desired behaviour? Kasperska and Słota have gone the opposite way. The idea was: how to embedding the optimization in simulation on System Dynamics models? In work [7, the attention has been focused on two methods of embedding the optimization in simulation. One of them took advantage from linear programming. However the second considered the idea of Legras (for pseudosolution of overdetermined system). Such "hybrid" ideas has enriched the possibilities of classical System Dynamics, specially in context of measuring the interesting aspect of dynamical behaviour of system. Now authors present extended version of model DYNBALANCE(2-2) (named: DYNBALANCE(2-2-c)) and some results of experiments undertaken by applying language Professional Dynamo 4.0.

\section{Mathematical Model of the System}

On Figure 1 the reader can study the main structure of the model, in Łukaszewicz symbols [10]. Below the meanings of matrixes: $A, x$ and $b$ can be recognize in presented matrix equation $A x=b$ : 


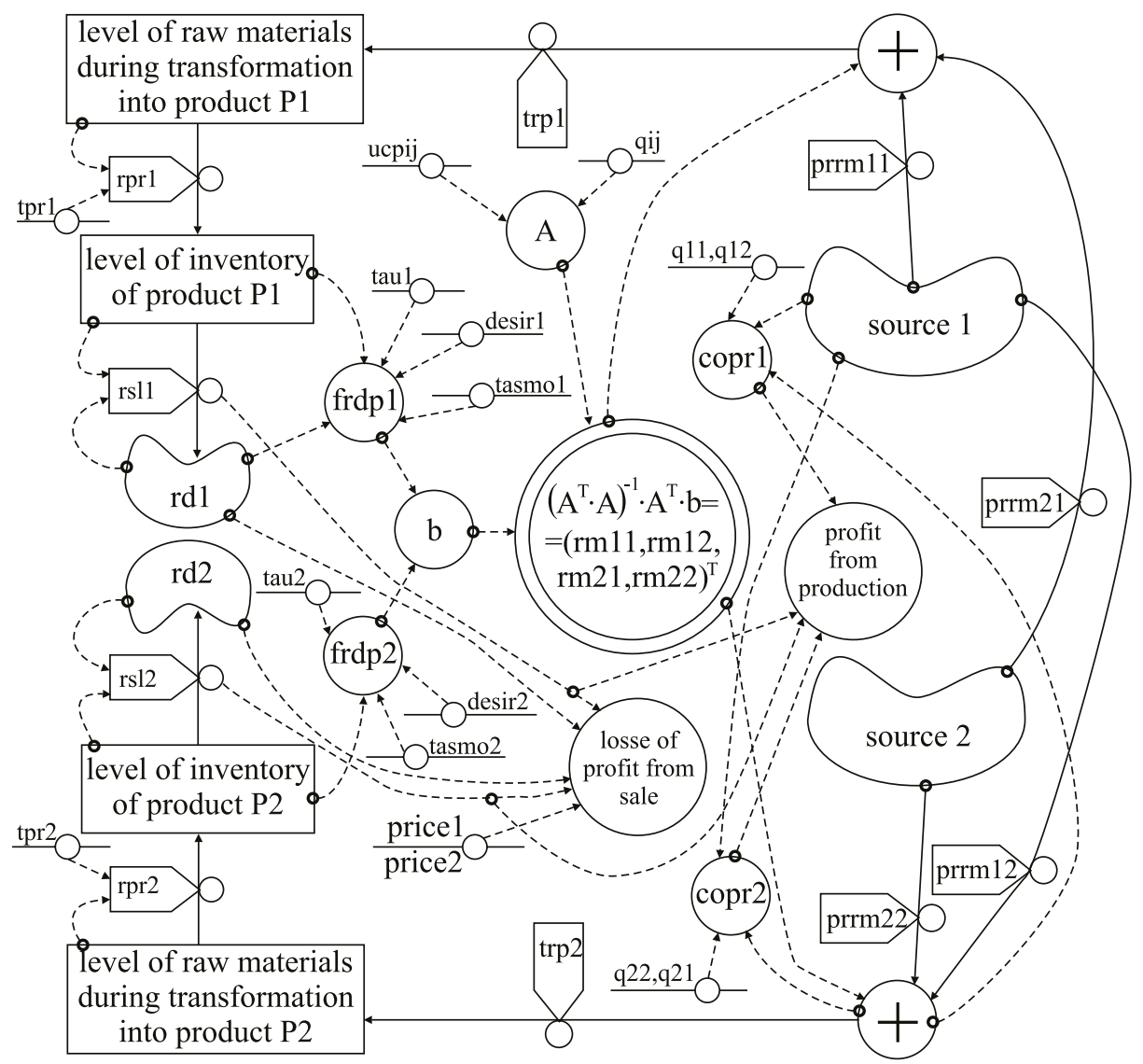

Fig. 1. Structure of model DYNBALANCE(2-2-c)

$\left(\begin{array}{cccc}q 11 & 0 & q 12 & 0 \\ 0 & q 21 & 0 & q 22 \\ 1 & 1 & 0 & 0 \\ 0 & 0 & 1 & 1 \\ u c p 11 \cdot q 11 & 0 & u c p 21 \cdot q 12 & 0 \\ 0 & u c p 12 \cdot q 21 & 0 & u c p 22 \cdot q 22 \\ 1 & 0 & 0 & 0 \\ 0 & 1 & 0 & 0 \\ 0 & 0 & 1 & 0 \\ 0 & 0 & 0 & 1\end{array}\right)\left(\begin{array}{c}r m 11 \\ r m 12 \\ r m 21 \\ r m 22\end{array}\right)=\left(\begin{array}{c}f r d p 1(t) \\ f r d p 2(t) \\ \operatorname{sourc} 1(t) \\ \operatorname{sourc} 2(t) \\ b 5 \\ b 6 \\ b 7 \\ b 8 \\ b 9 \\ b 10\end{array}\right)$

The idea of solving the matrix equation (10) uses the method of Legras [9] by finding the so called "pseudosolution", which minimize the norm of overdetermined equation (11). This is the Euclidean norm, so it is the square root of sum 
of squares of discrepancies $(A x-b)_{i}$, for $i=1,2, \ldots, 10$. So, the found solution is that give the best "fitting" of balance (modelling by equation (11)).

Technically speaking, the solving of matrix equation (1) is the problem of programming specific works on matrixes, in order to attain $x$ :

$$
x=\left(\begin{array}{l}
r m 11 \\
r m 12 \\
r m 21 \\
r m 22
\end{array}\right)=\left(A^{T} \cdot A\right)^{-1} \cdot A^{T} \cdot b .
$$

The formula was examined by authors and for given number values we have gotten results, that will be described in next section.

\section{The Assumptions for Experiments}

The table 1 presents in synthetical form the elements of scenario of simulations experiments.

Table 1. The main assumptions for experiments on model DYNBALANCE(2-2-c) (where $\mathbf{1}(t)$ is the unit step function, equal to 0 for $t<0$ and 1 for $t \geq 0$ )

\begin{tabular}{|c|c|c|}
\hline No. & $r d 1$ & $r d 2$ \\
\hline 1 & $\begin{array}{l}\text { Sinusoidal: } \\
r d 1(t)=100+30 \sin (\pi t / 52)\end{array}$ & $\begin{array}{l}\text { Sinusoidal: } \\
r d 2(t)=100+30 \sin (\pi t / 52)\end{array}$ \\
\hline 2 & $\begin{array}{l}\text { Step function (increase): } \\
r d 1(t)=100+300 \mathbf{1}(t-10)\end{array}$ & $\begin{array}{l}\text { Sinusoidal: } \\
r d 2(t)=100+30 \sin (\pi t / 52)\end{array}$ \\
\hline 3 & $\begin{array}{l}\text { Step function (decrease): } \\
r d 1(t)=100-100 \mathbf{1}(t-10)\end{array}$ & $\begin{array}{l}\text { Sinusoidal: } \\
r d 2(t)=100+30 \sin (\pi t / 52)\end{array}$ \\
\hline 4 & $\begin{array}{l}\text { Linear decrease: } \\
r d 1(t)= \begin{cases}1000 & t<10 \\
1100-10 t & t \geq 10\end{cases} \end{array}$ & $\begin{array}{l}\text { Sinusoidal: } \\
r d 2(t)=100+30 \sin (\pi t / 52)\end{array}$ \\
\hline 5 & $\begin{array}{l}\text { Step function (increase): } \\
r d 1(t)=100+300 \mathbf{1}(t-10)\end{array}$ & $\begin{array}{l}\text { Step function (decrease): } \\
r d 2(t)=100-100 \mathbf{1}(t-10)\end{array}$ \\
\hline
\end{tabular}

Moreover the values of chosen parameters are as follows:

- prices: price $1=300$, price $2=350$;

- sources of raw materials: $\operatorname{sourc} 1=20, \operatorname{sourc} 2=20$;

- initial levels of inventory of product $P 1$ and $P 2: \operatorname{lin} 1=350, \operatorname{lin} 2=350$;

- initial levels of raw materials during transformation into product $P 1$ and $P 2: \operatorname{lm} t 1=200, \operatorname{lm} t 2=400$;

- parameters of technology: $q 11=1, q 12=2, q 21=1, q 22=2$.

The possibilities of experimentations on model DYNBALANCE(2-2-c) are practically unlimited. For example: the prices can become random as sources of raw materials too. Below, in the next section, the chosen results of experiments 15 will be presented. 


\section{The Results of Experiments}

On Figures 2 6 the main characteristic of some variables from the model DYNBALANCE(2-2-c) are presented. The Reader, who will be interested in details, has possibilities to compare such important (in sense of "quality" of fitting the balance: $A x=b$, and in sense of dynamics of whole system) variables, like: norm, $\operatorname{lin} 1, \operatorname{lin} 2$, prof 1, prof 2 and the others.
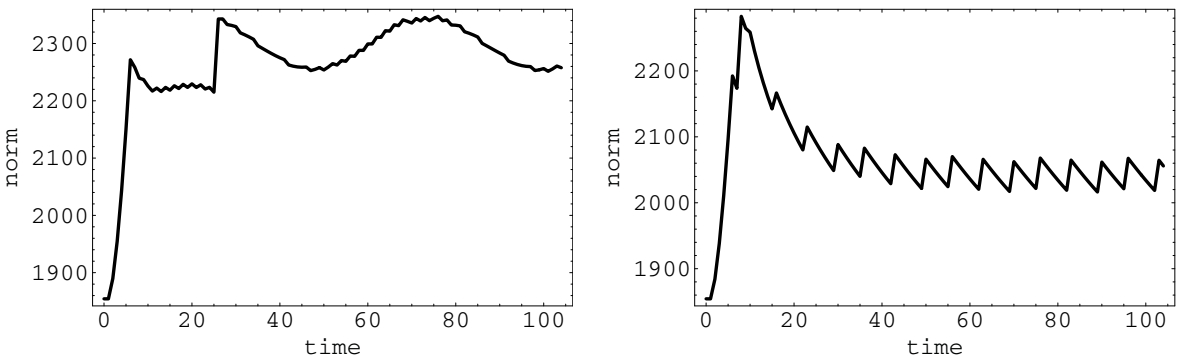

Fig. 2. The characteristic of variable norm (the "fitting of balance $A x=b$ in whole horizon of simulation; left figure - experiment number 1, right figure - experiment number 5)
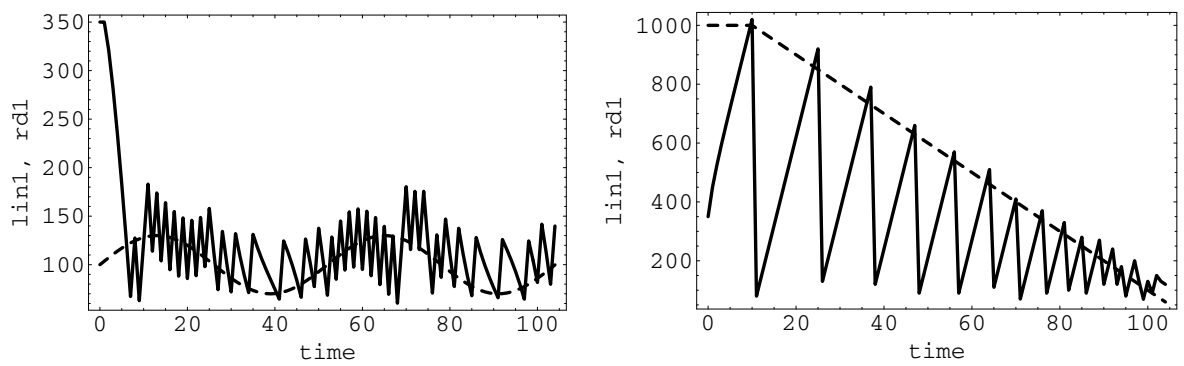

Fig. 3. The characteristic of level of inventory of product $P 1(\operatorname{lin} 1)$ and rate of demand $r d 1$ (left figure - experiment number 1, right figure - experiment number 4; solid line $\operatorname{lin} 1$, dash line - rd1)

Under the different condition about the demands for product $P 1$ and $P 2$ system reacts in such a way that minimize the Euclidean norm. So, the rates of raw materials: $r m 11, r m 12$ and $r m 22$, are optimal to fit the balance $A x=b$ (see Figure 1) and the "quality" of fitting, variable norm has optimal value in each step of simulation (in whole horizon two years). So, the embedding optimization in simulation, has dynamical character and is "compatible" with idea of dynamical modelling in Forrester's way. Precisely speaking, it's some extension of System Dynamics method possibilities. 

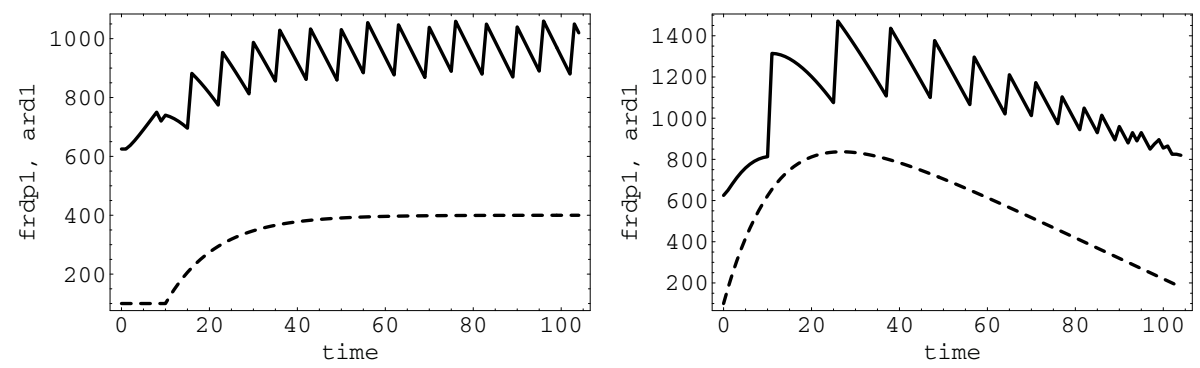

Fig. 4. The characteristic of plan of production of product $P 1$ ( $f r d p 1)$ and averaging rate of demand ard 1 (left figure - experiment number 2, right figure - experiment number 4 ; solid line $-\operatorname{frdp} 1$, dash line $-\operatorname{ard} 1)$
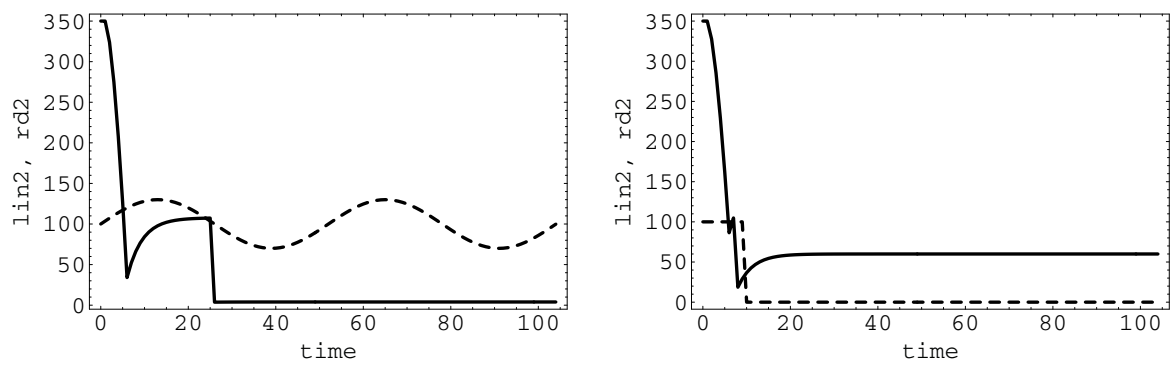

Fig. 5. The characteristic of level of inventory of product $P 2(\operatorname{lin} 2)$ and rate of demand $r d 2$ (left figure - experiment number 3, right figure - experiment number 5 ; solid line $\operatorname{lin} 2$, dash line $-r d 2)$
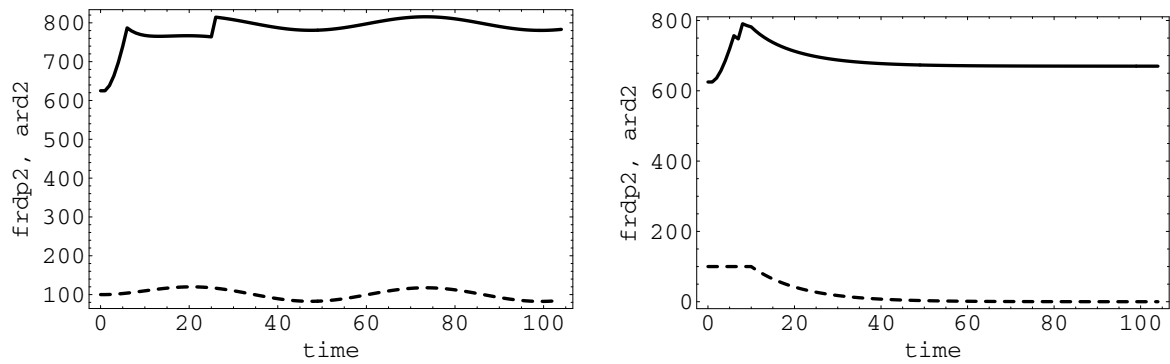

Fig. 6. The characteristic of plan of production of product $P 2(f r d p 2)$ and averaging rate of demand ard2 (left figure - experiment number 4, right figure - experiment number 5 ; solid line $-\operatorname{frdp2}$, dash line $-\operatorname{ard} 2)$

\section{$5 \quad$ Final Remarks and Conclusions}

The purpose of the paper was to present some results of experiments undertaken on model DYNBALANCE(2-2-c). Such experiments consider the problem of optimization embedded in simulation. The authors have linked the algorithm 
of solving the pseudosolution of overdetermined system of equation to classical structure of type System Dynamics. Final conclusions are as follows:

- simulation on models type System Dynamics, linked with optimization technique, is a good tool for analysing the dynamical, complex, nonlinear, multilevel system;

- the locally optimal decisions can be confront with dynamic of a system like a whole - its give the supportive tool for decision-makers and for the projectors of the information- decision systems as well;

- if seems that such "hybrid" ideas, like presented in paper, has a future that enrich the possibilities of famous Forrester's method and makes them adequate to different situations in real systems.

\section{References}

1. Coyle, R.G.: System Dynamics Modelling. A Practical Approach. Chapman \& Hall, London (1996)

2. Coyle, R.G.: The practice of System Dynamics: milestones, lessons and ideas from 30 years experience. System Dynamics Rev. 14 (1998) 343-365

3. Forrester, J.W.: Industrial Dynamics. MIT Press, Massachusetts (1961)

4. Forrester, J.W.: Principles of Systems. Cambridge Press, Massachusetts (1972)

5. Kasperska, E., Mateja-Losa, E., Słota, D.: Some extension of System Dynamics method - practical aspects. In: Deville, M., Owens, R. (eds.): Proc. 16th IMACS World Congress. IMACS, Lausanne (2000) 718-11 1-6

6. Kasperska, E., Słota, D.: Mathematical Method in the Management in Conceiving of System Dynamics. Silesian Technical University, Gliwice (2000) (in Polish)

7. Kasperska, E., Słota, D.: Two different methods of embedding the optimization in simulation on model DYNBALANCE(2-2). In: Davidsen, P.I., Mollona, E. (eds.): Proc. 21st Int. Conf. of the System Dynamics Society. SDS, New York (2003) 1-23

8. Kasperska, E., Słota, D.: The Estimation of the Mathematical Exactness of System Dynamics Method on the Base of Some Simple Economic System. In: Bubak, M., Albada, G.D., Sloot, P.M.A., Dongarra, J.J. (eds.): Computational Science, Part II. LNCS 3037, Springer-Verlag, Berlin (2004) 639-642

9. Legras, J.: Methodes et Techniques De'Analyse Numerique. Dunod, Paris (1971)

10. Łukaszewicz, R.: Management System Dynamics. PWN, Warsaw (1975) (in Polish)

11. Sterman, J.D.: Business dynamics - system thinking and modeling for a complex world. Mc Graw-Hill, Boston (2000) 